Revista Brasileira de Farmacognosia Brazilian Journal of Pharmacognosy 21(3): 556-559, May./Jun. 2011

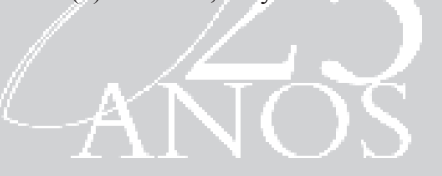

Short Communication

Received 14 Jul 2010

Accepted 23 Sep 2010

Available online 4 Mar 2011

Keywords:

Gochnatia polymorpha subsp.

floccosa

Asteraceae

triterpenes

ISSN 0102-695X

doi: $10.1590 / \mathrm{S} 0102-695 \times 2011005000031$

\section{Triterpenes from the flowers of Gochnatia polymorpha subsp. floccosa}

\author{
Luana B. Silva, ${ }^{1}$ Regiane L. B. Strapasson, ${ }^{1}$ Dilamara Riva, ${ }^{1}$ \\ Marcos J. Salvador, ${ }^{2}$ Maria Élida A. Stefanello ${ }^{*}$,
}

${ }^{I}$ Departamento de Química, Universidade Federal do Paraná, Brazil, ${ }^{2}$ Instituto de Biologia, Departamento de Biologia Vegetal, Curso de Farmácia, Universidade Estadual de Campinas, Brazil.

\begin{abstract}
Phytochemical study of the flowers of Gochnatia polymorpha subsp. floccosa, Asteraceae, yielded eleven known triterpenes identified as lupeol, lupeyl acetate, lupeyl palmitate, taraxasterol, taraxasteryl acetate, pseudotaraxasterol, pseudotaraxasterol acetate, $\alpha$-amyrin, $\alpha$-amyryl palmitate, $\beta$-amyrin and $\beta$-amyryl palmitate, along with sitosterol, stigmasterol, palmitic and stearic acids. These compounds are been reported for the first time in the species. The compounds were identified by analysis of NMR spectra $\left({ }^{1} \mathrm{H},{ }^{13} \mathrm{C}\right.$ and DEPT), GC-MS and comparison with literature data. Previous work have reported the isolation of triterpenes, diterpenes, sesquiterpenes, flavonoids, coumarins and phenolic compounds from aerial parts and roots from $G$. polymorpha.
\end{abstract}

\section{Introduction}

Gochnatia polymorpha (Less.) Cabrera comprises three subspecies, with different distribution areas. The subspecies polymorpha is found in Southeastern of Brazil and Paraguay, the subspecies ceanothifolia is distributed in South of Brazil, Paraguay, Uruguay and Argentine, and the subspecies floccosa is limited to Southeast and South of Brazil (Cabrera \& Klein, 1973). The genus Gochnatia is characterized by the production of sesquiterpene lactones, along with sesquiterpenes, diterpenes, triterpenes, acetylenes, flavonoids and coumarins (Catalan et al., 1996). Previous studies on G. polymorpha subsp. unspecified, reported the isolation of the triterpene bauerenyl acetate and dehydrocostus lactone from the bark and trunk bark (Farias et al., 1984), sesquiterpenes, sesquiterpene lactones and dimeric lactones from the roots and aerial parts (Bohlmann et al., 1986), flavonoids, phenolic compounds and a proline derivative from more polar extracts from leaves (Moreira et al., 2000), and essential oil of the wood (Lima et al., 2007). The studies on $G$. polymorpha subsp. polymorpha have reported the isolation of sesquiterpene lactones, diterpenes, triterpenes, flavonoids and coumarins from the roots and aerial parts (Sacilotto et al., 1997; Catalan et al., 2003). The essential oil composition and antimicrobial activity has been reported for Gochnatia polymorpha subsp.floccosa (Stefanello et al., 2006a, b), but there are no phytochemical investigations on this subspecies.

The present work describes, for the first time, the phytochemical study of the flowers of $G$. polymorpha subsp. floccosa.

\section{Materials and Methods}

NMR experiments were acquired on a Bruker AC-200 NMR, observing ${ }^{1} \mathrm{H}$ and ${ }^{13} \mathrm{C}$ at 200 and 50 $\mathrm{MHz}$, respectively. $\mathrm{CDCl}_{3}$ was used as solvent and TMS as internal reference. The fatty acid methyl esters were analyzed by GC-EIMS (70 eV) using a Varian Saturn 2000 GC/MS spectrometer equipped with a CP-Sil$8 \mathrm{CB}$ capillary column $(30 \mathrm{~m} \times 0.25 \mathrm{~mm}, 0.25 \mu \mathrm{m}$ film thickness), which was operated at $60{ }^{\circ} \mathrm{C}$ for $3 \mathrm{~min}$, and then programmed from $60-220^{\circ} \mathrm{C}$ at $5^{\circ} \mathrm{C} / \mathrm{min}$, after which it was kept isothermal at $220^{\circ} \mathrm{C}$ for $5 \mathrm{~min}$. The carrier gas was helium ( $1 \mathrm{~mL} / \mathrm{min})$ and the injector temperature was $250{ }^{\circ} \mathrm{C}$. The compounds were identified by comparison of their retention indices (RI), calculated in relation to n-alkanes, and mass spectra with those found in the literature (Adams, 2007). Silica gel (Merck, 230-400 mesh) was used for column chromatographic separation (CC), while silica gel $60 \mathrm{PF}_{254}$ (Merck) was used for analytical (TLC, $0.25 \mathrm{~mm}$ ) and preparative (PTLC, 
$1.0 \mathrm{~mm}$ ) thyn layer chromatography. Compounds were visualized by exposure under $\mathrm{UV}_{254 / 366}$ light and spraying with $5 \%(\mathrm{v} / \mathrm{v}) \mathrm{H}_{2} \mathrm{SO}_{4}$ in ethanol solution, followed by heating on a hot plate.

Flowers of Gochnatia polymorpha subsp. floccosa Cabrera, Asteraceae, were collected on March 2004, in Curitiba, Paraná State, Brazil. The plant was identified by Dr. Armando Carlos Cervi and a voucher specimen was deposited in the herbarium of Universidade Federal do Paraná, in Curitiba, Paraná State, Brazil (UPCB 30100).

The air-dried flowers (126.8 g) were extracted exhaustively by maceration at room temperature with hexane and ethanol, successively. Crude ethanol extract $(6.9 \mathrm{~g})$, after removal solvent under reduced pressure, was suspended in EtOH: $\mathrm{H}_{2} \mathrm{O}$ 1:1 and then extracted with $\mathrm{CH}_{2} \mathrm{Cl}_{2}$. The organic layer was separated and the solvent removed to give the residue $(2.7 \mathrm{~g})$. This was submitted to silica gel CC, eluted with increasing amounts of EtOAc in hexane to give eleven fractions. Fraction $2(291.0 \mathrm{mg})$ was subjected to another $\mathrm{CC}$ eluted with hexane:EtOAC $95: 5$, yielding three subfrations. The subfraction 2.3 (102.8 mg) was purified by repeated PTLC eluted with pentane:EtOAc 95:5 to give M1 (13.6 mg, 2+5+7) and M2 (14.9 mg, 3+9+11). Fraction 6 (54.8 mg) was purified by repeated PTLC, eluted with hexane: $\mathrm{CH}_{2} \mathrm{Cl}_{2}$ :EtOAc 2:1:0.5 to give M3 $(7.2 \mathrm{mg}, \mathbf{1 + 4 + 6 + 8 + 1 0})$. Fraction 7 (49.1 mg) was purified by repeated PTLC eluted in hexane: $\mathrm{CH}_{2} \mathrm{Cl}_{2}$ 1:1 to give M4 (7.0 mg, palmitic + stearic acids). Fraction $8(35.0 \mathrm{mg})$ was purified by PTLC eluted with hexane:EtOAc 8:2 to give M5 (12.2 mg, sitosterol + stigmasterol).

\section{Results and Discussion}

Chromatographic fractionation on silica gel of extracts rich in triterpenes commonly yields mixtures instead pure compounds. The identification of components can be achieved using standards and GCMS analysis, or by careful analysis of NMR spectra of the mixture. The ${ }^{1} \mathrm{H}-\mathrm{NMR}$ provides little information about structure of triterpenes, but ${ }^{13} \mathrm{C}$-NMR and DEPT are very useful. The most triterpenes found in vegetal extracts are pentacyclic or tetracyclic, with only one oxygenation on C-3 and one or two double linkage. In these cases, the type of the triterpene can be determined by chemical shifts and multiplicity of the carbons of the double linkage (Gallegos \& Roque, 1990). This approach was applied in this work to identify the compounds found in the flowers of Gochnatia polymorpha subsp. floccosa.

The dichloromethane fraction of ethanol extract of flowers of $G$. polymorpha subsp. floccosa yielded mixtures (M1-M5) of triterpenes, steroids and fatty acids, which exhibited a single spot when analyzed by TLC in several solvents.

The ${ }^{13} \mathrm{C}-\mathrm{NMR}$ spectra of M1 showed sixtyseven signals, indicating a triterpene mixture. In particular was observed six signals for olefinic carbons, being two secondary $(\delta 107.1$ and 109.4$)$, one tertiary $(\delta$ $118.9)$ and three quaternary carbons $(\delta 139.8,151.0$ and 154.6). Comparison with literature data suggested the presence of triterpenes type lup-20(29)-ene $(\delta 109.4$ and $151.0)$, urs-20(30)-ene ( $\delta 107.1$ and 154.6) and urs-20ene ( $\delta 118.9$ and 139.8) (Gallegos \& Roque, 1990). Also was observed an intense signal at $\delta 81.0$, typical of an acetylated triterpene, and a signal for an ester carbonyl ( $\delta$ 171.0). There were no others signals for oxygenated carbons. Thus the components of M1 were identified as lupeyl acetate (2), taraxasteryl acetate (5) and pseudotaraxasteryl acetate (7) (Gallegos \& Roque, 1990; Mahato \& Kundu, 1994; Silva et al., 1998) (Figure 1). The presence of acetates was corroborated by ${ }^{1} \mathrm{H}$ NMR that showed two singlets at $\delta 2.04$ and 2.05. In addition also were observed signals for oxymethine $(\delta 4.48)$ and olefinic protons of $\mathbf{2}(\delta 4.57$ and 4.67), 5 ( $\delta .41)$ and 7 ( $\delta$ 5.26).

The ${ }^{13} \mathrm{C}$-NMR spectrum of M2 also showed more than sixty peaks, as M1. The signals of the olefinic carbons indicated the presence of three triterpenes type lup-20(29)-eno ( $\delta 109.3$ and 150.9), urs-12-ene $(\delta 124.3$ and 139.6) and olean-12-ene $(\delta 121.6$ and 145.2). The chemical shift of oxygenated carbon also was characteristic of an ester triterpene $(\delta 80.6)$, but the carbonyl group was more deshielded $(\delta 174.7)$ than in M1. In the ${ }^{1} \mathrm{H}$ NMR spectrum there were no signals for acetyl groups, but it was observed an intense signal at $\delta 1.25$, typical of a long chain carbon. These data suggested the presence of triterpenes esterified with fatty acids. In order to identify the fatty acids, M2 was submitted to transesterification reaction with $\mathrm{MeONa} /$ $\mathrm{MeOH}$ (Mendes et al., 1999). After the usual work-up was obtained one fraction containing the sesquiterpene alcohols and another containing the fatty acid methyl esters. The last one was analyzed by GC-MS and showed only one compound (RI 1922), which was identified as methyl palmitate by its retention index, comparison with authentic sample and mass spectrum (Adams, 2007). Therefore, the components of M2 were identified as lupeyl palmitate (3), $\alpha$-amyryl palmitate (9) and $\beta$-amyryl palmitate (11) (Figure 1). Mixtures with similar composition have been previously reported in Vernonia tweediana (Diaz et al., 2008) and Tapirira guianensis (Correia et al., 2008).

The ${ }^{13} \mathrm{C}$ NMR spectra of M3 showed, in addition several signals for C-sp3, ten peaks for olefinic carbons, compatible with the presence of five triterpenes, type lup$20(29)$-ene $(\delta 109.3$ and 150.9$)$, urs-20(30)-ene $(\delta 107.0$ and 154.8), urs-20-ene ( $\delta 118.9$ and 139.5), urs-12-ene $(\delta$ 124.1 and 139.9) and olean-12-ene ( $\delta 121.7$ and 145.1). 
Also was observed a signal at $\delta 79.0$, characteristic of oxymethine carbon of triterpene alcohol with the hydroxyl group $\beta$-orientated (Gallegos \& Roque, 1990). This data suggested the presence of lupeol (1), taraxasterol (4), pseudotaraxasterol (6), $\alpha$-amyrin (8) and $\beta$-amyrin (10) (Mahato \& Kundu, 1994) (Figure 1). This composition was confirmed by ${ }^{1} \mathrm{H}$ NMR spectrum that showed signals for oxymethine protons $(\delta 3.22)$ and olefinic protons of 1 ( $\delta 4.57$ and 4.69$), 4(\delta .4 .62)$, $\mathbf{6}(\delta 5.26), \mathbf{8}(\delta .5 .17)$ and $\mathbf{1 0}(\delta 5.13)$.

The mixture M4 showed NMR data typical of fatty acids. Esterification with $\mathrm{MeOH}$ yielded a mixture of palmitic and stearic methyl esters, which was identified by GC-MS based on their retention indices (1922 and 2122) and comparison of their mass spectra with literature (Adams, 2007) and with authentic sample.

The mixture M5 showed NMR data identical to those reported for the known mixture of the steroids sitosterol and stigmasterol (Goulart et al., 1993).

The identified triterpenes are been reported for the first time in G. polymorpha. The triterpene lupeol (1) was previously reported in the flowers of G. blanquetiana, along with sitosterol glycoside, kaempferol glycoside and 4-hydroxy- $N$-methylproline (Lima et al., 2003). Others phytochemical studies on flowers of Gochnatia species were not found.<smiles>[R6][C@H]1CC[C@@]2(C)[C@@H](CC[C@]3(C)[C@H]2CC[C@H]2[C@@H]4[C@H](C(=C)C)CC[C@]4(C)CC[C@@]23C)C1(C)C</smiles>

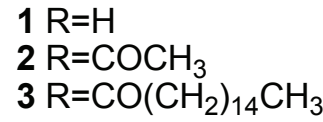<smiles>[R6][C@H]1CC[C@@]2(C)[C@@H](CC[C@]3(C)[C@H]2CC[C@H]2[C@@H]4[C@H](C)C(=C)CC[C@]4(C)CC[C@@]23C)C1(C)C</smiles>

$4 \mathrm{R}=\mathrm{H}$ $5 \mathrm{R}=\mathrm{COCH}_{3}$<smiles>[R6][C@H]1CC[C@@]2(C)[C@@H](CC[C@]3(C)[C@H]2CC[C@H]2[C@@H]4[C@H](C)C(C)=CC[C@]4(C)CC[C@@]23C)C1(C)C</smiles>

$6 \mathrm{R}=\mathrm{H}$

$7 \mathrm{R}=\mathrm{COCH}_{3}$<smiles>[R6][C@H]1CC[C@@]2(C)[C@@H](CC[C@]3(C)[C@H]2CC=C2[C@@H]4[C@H](C)[C@@H](C)CC[C@]4(C)CC[C@@]23C)C1(C)C</smiles>

$8 \mathrm{R}=\mathrm{H}$

$9 \mathrm{R}=\mathrm{R}=\mathrm{CO}\left(\mathrm{CH}_{2}\right)_{14} \mathrm{CH}_{3}$<smiles>[R6][C@H]1CC[C@@]2(C)[C@@H](CC[C@]3(C)[C@H]2CC=C2C4CC(C)(C)CC[C@]4(C)CC[C@@]23C)C1(C)C</smiles>

$10 \mathrm{R}=\mathrm{H}$

$11 \mathrm{R}=\mathrm{R}=\mathrm{CO}\left(\mathrm{CH}_{2}\right)_{14} \mathrm{CH}_{3}$

\section{Acknowledgements}

This work was supported by Fundação Araucaria. The authors are grateful to Dr. Armando C. Cervi (Departamento de Botânica, UFPR) for plant identification. RLBS is grateful to CNPq for scholarship and MJS to FAPESP for financial support.

\section{References}

Adams RP 2007. Identification of Essential Oils Components by Gas Chromatography/ Mass Spectrometry, Allured
Publ. Corp., Carol Stream, IL.

Bohlmann F, Zdero C, Schmeda-Hirschmann G, Jakupovic J, Dominguez XA, King RM, Robinson H 1986. Dimeric guainolides and other constituents from Gochnatia species. Phytochemistry 25: 1175-1178.

Cabrera AL, Klein RM 1973. Compostas - Tribo Mutisiae. In: Reitz R (org.). Flora Ilustrada Catarinense. Itajaí: Herbário Barbosa-Rodrigues, p. 29-35.

Catalan CAN, Borkosky SA, Joseph-Nathan P 1996. The secondary metabolite chemistry of the subtribe Gochnatiinae (tribe Mutisieae, family Compositae). Biochem Syst Ecol 24: 659-718. 
Catalan CAN, Vega MI, Lopez ME, Cuenca MR, Gedris TE, Herz W 2003. Coumarins and a kaurane from Gochnatia polymorpha ssp polymorpha from Paraguay. Biochem Syst Ecol 31: 417-422.

Correia SJ, David JM, Silva EP, David JP, Lopes LMX, Guedes MLS 2008. Flavonóides, norisoprenoides e outros terpenos das folhas de Tapira guianensis. Quim Nova 31: 2056-2059.

Diaz G, Nogueira MA, Olguin CFA, Somensi A, Vidotti GJ 2008. Estudo fitoquímico e biológico de Vernonia tweediana Baker (Asteraceae). Lat Am J Pharm 27: 5661.

Farias ACM, Silva AJR, Tomassini TCB 1984. Constituents of Mochinea polymorpha. J Nat Prod 47: 363-364.

Gallegos RS, Roque NF 1990. Análise de misturas de triterpenos por RMN ${ }^{13}$ C. Quim Nova 13: 278-281.

Goulart MOF, Santana AEG, Lima RA, Cavalcante SH, Carvalho MG, Braz-Filho R 1993. Fitoconstituintes químicos de Jatropha elliptica. Atribuição dos deslocamentos químicos dos átomos de carbono e hidrogênio dos diterpenos jatrofolonas A e B. Quim Nova 16: 95-100.

Lima MCL, Lemos TLG, Braz-Filho R, Pessoa ODL 2003. Chemical constituents from the flowers of Gochnatia blanquetiana (DC) Cabrera. Rev Latinoam Quim 31: 85-88.

Lima SR, Oliveira GS, Morais SAL, Nascimento EA, Chang R 2007. Estudo dos constituintes macromoleculares, extrativos voláteis e compostos fenólicos da madeira de candeia - Moquinia polymorpha (Less) DC. Cien Florestal 17: 145-155.

Mahato SB, Kundu AP 1994. 13C NMR spectra of pentacyclic triterpenoids - a compilation and some salient features. Phytochemistry 37: 1517-1575.
Mendes CC, Cruz FG, David JM, Nascimento IP, David JP 1999. Triterpenos esterificados com ácidos graxos e ácidos triterpênicos isolados de Byrsonima microphylla. Quim Nova 22: 185-188.

Moreira AS, Spitzer V, Schapoval EES, Schenkel EP 2000. Antiinflammatory activity of extracts and fractions from the leaves of Gochnatia polymorpha. Phytother Res 14: 638-640.

Sacilotto ACB, Vichnewski W, Herz W 1997. Ent-kaurene diterpenes from Gochnatia polymorpha var. polymorpha. Phytochemistry 44: 659-661.

Silva JRA, Rezende CM, Pinto AC, Pinheiro MLB, Cordeiro MC, Young CM, Bolzani VS 1998. Ésteres triterpênicos de Himatanthus sucuuba (Spruce) Woodson. Quim Nova 21: 702-704.

Stefanello MEA, Cervi AC, Wisniewski-Junior A, Simionatto EL 2006a. Óleo essencial de Gochnatia polymorpha (Less) Cabr. ssp. floccosa Cabr. Quim Nova 29: 9991002 .

Stefanello MEA, Salvador MJ, Ito IY, Macari PAT 2006b. Avaliação da atividade antimicrobiana e citotóxica de extratos de Gochnatia polymorpha ssp. floccosa. Rev Bras Farmacogn 16: 525-530.

\section{*Correspondence}

Maria Élida A. Stefanello

Departamento de Química, Universidade Federal do Paraná 81530-900 Curitiba-PR, Brazil

elida@ufpr.br

Tel. +554133613177

Fax: +55 4133613186 